case and going into the funest details of diagnosis. Neither Tiirk nor Srhmidt, formerly popular in the medical courses, are teaching at present.

The buildings of the new Cieneral Hospital are nearing completion, across the strect from the pathologic department. Some of the present ones date from 1784 , so that the contrast is great between the old and the new. The nearness of the new buildings will conduce to the same concentration of material in one great center which constitutes the chief advan. tage in medical study in Vienna as compared with any other clinic in the world.

We have heard so much in America of the work of Wright and the opsonic theory that I have been interested in noting the extremely conservative attitude of Vienna on the subject. An assistant in Neusser's clinic has, however, just returned from London, and is making preparations to carry on extensive investigations along this line.

There has been a certain evil tendency heretofore to attempt to substitute other methods of laboratory research for the less brilliant and often more difficult procedures of a more purely elinical nature. We ought to impress on the students that the new methods are additions to and not substitutes for our present armamentarium.

Finally, it is gratifying to hear more frequently than formerly the names of the more prominent American authoritiesperhaps rather more the surgical than the medical ones. The international medical and surgical congresses have doubtless aided in some degree to bring this about. J. N. HALL, M.D.

\section{The Bedbug May Have Other Hosts Than Man.}

\section{Detroit, Nov. 30, 1907.}

To the Editor:-The question has been asked a number of times of late: "Can the bedbug live on other animals besides man?" I answer this positively: "Yes." In this laboratory (the biologic laboratory of Parke, Davis \& Co.) we purposely raise tens of thousands of bedbugs, using the guinea-pig as host, for the purpose of testing the efficacy of insecticides, as we find them much more resistant to such than any of our common insects.

It should be noted that there are a number of allied species living on birds, bats and beetles, that are often supposed to be true bedbugs, but are not. I sent a number of the bedbugs raised on our guinea-pigs, to the Bureau of Entomology at Washington, where they confirmed our opinion that these were the genuine Cimex lectularis, or human bedbug. The entomologists state that in our northern communities there is but one brood of eggs laid and hatehed each year. This is apparently a mistake, if wo may judge from our guinea-pigs. While they are more numerous, apparently breeding faster in summer-time, they appear to reproduce throughout the year.

That the bedbug might be a means of transferring disease was pointed out many years ago. Interest in the subject revived when it was shown that malaria, yellow fever and probably bubonic plague were transmitted at least largely through the agency of insects. A little experimental work has been done, but so far as I have been able to find, while there is every probability that the bedbug can transmit disease, there is little in the way of positive proof of this opinion. The bedbug has been suspected of being able to transmit the fol. lowing diseases: Leprosy, lupus, syphilis, plague, pneumonia, typhoid, relapsing fever, anthrax, some of the skin diseases, and possibly carcinoma.

The world-wide distribution of the bedbug, its nocturnal feeding habits, make it often impossible to avoid its attack. Again, its resistance to starvation and to the various would-be insecticides makes it most difficult to get rid of the pest once it is present. Packard, who was one of our most reliable entomologists, states that these bedbugs will live for a year to a year and a half without food or drink, enclosed in a bottle These facts may account for their remaining in uninhabited houses for years and their unexpected and apparently unaccountable transference from house to house.

Attempting to show that the bedbug can take a disease from one animal and transfer it to another, I have inoculated guinea-pigs with anthrax, placed them in glass jars, and then placed in the jars several starved bedbugs. On washing and crushing these bugs the next day, the anthrax germs were easily demonstrated within their bodies, and from such we have cultivated the germs. But this, of course, does not prove that this bedbug, biting another animal, will transmit the disease, although the presumptive evidence is strong. So far I have no positive proof. The difficulty in the way is that the hungry bedbug will gorge himself with the blood of the defenseless animal, and probably will not want to feed again for a week or so. Meantime the germs taken into its stomach, it may be, are digested or in some manner destroyed, and so, except for the possible clinging of germs to its biting apparatus, there might be little possibility of transference of the disease to the second animal.

The conditions in the case of the human being are very favorable, as the bite of the bug usually makes the individual restless, he turns over and often attempts to rid himself of the pest, so that it may well happen that the bug will be only partially satisfied and ready to attack another individual, who may occupy the same room or bed, the next night.

\section{Cinaries T. McClintock, M.D.}

\section{Hemorrhage from the Bowel Following Appendectomy.}

New York CrTy, Nov. 29, 1907.

To the Editor:-I have just read the interesting article by Dr. J. R. Judd of Honolulu on the above subject in THE JourNAL, November 30 , page 1843 . He asks this question:

"Why may it not be that in some cases of hemorrhage from the bowel following appendectomy there is a condition similar to that of hematemesis following abdominal operation?" $\mathrm{He}$ then quotes Walch's case from Kelly's book, which in all prob. ability was hemorrhage from a gastric or duodenal ulcer since there was vomiting of blood. As the operator has used a simple ligature around the stump of the appendix, and since hemorrhage did not occur until six days after the operation, bleeding from the stump, in my opinion, was precluded.

I have made diligent inquiries by correspondence and personally and before the large assembly of operators, at the meeting at Atlantic City in June, 1907, and have yet failed to obtain a record of a single case of accident occurring after the application of the silk ligature to the stump of the appendix, no other procedure being done.

The single case mentioned by Dr. Judd was evidently not connected with the operation on the appendix. From this it is evident that there is a greater danger from any method of suture which requires the insertion of a needle into the walls of the cecum, without regard to erushing the stump or stitching the open end or by inversion with double rows of superficial sutures, or by clipping off the appendix close to the level of the cecum and rolling in the stump, than by the simple ligation with silk with carbolic acid disinfection of the stump.

The least possible violence to the tissues in securing the lost possible result should be accepted as one of the cardinal principles of surgery. In my opinion it is violated in the unnecessary suturing of the cecal wall. In addition to the numerous cases of disaster already reported with the suture methor, others have come to mv notice but the demonstration is already so positive that their narration is unnecessary.

JOHN A. WYETI.

\section{Nostrum Prescribing.}

Pueblo, Colo., Nov. 28. 1907.

To the Editor:-I spent last month in New York (ity with some old-time friends in whose home is a small love A few days before my arrival this boy was out of sorts, an the father went to their physician for a prescription. Imagin my surprise to discover that the prescription that father re. ceived was for a bottle of Castoria-and there it was, literature, wrappers and all.

I looked up the directory of the American Medical Associntion only to find that this physician is not only a member of the state society, but also of the American Medical Asso:iation. And he orders Castoria! Is it because the children ' $r y$ for it? Riding up Fifth Avenue the other day the elegant home of Castoria's promoter was pointed out, and not far from 